\title{
Use of lasers in pediatric dentistry- A review
}

\author{
Shaik Ali Hassan ${ }^{1 *}$, Sumit Bhateja ${ }^{2}$ \\ ${ }^{1}$ Dental Surgeon, ${ }^{2}$ HOD, Dept. of Oral Medicine, ${ }^{1,2}$ Manav Rachna Dental College, Faridabad, Haryana, India
}

*Corresponding Author: Shaik Ali Hassan

Email: alishaikhassan@gmail.com

\begin{abstract}
Pediatric laser dentistry is a promising field in present day insignificantly obtrusive dentistry, and it tends to be "kid well disposed" approach. Laser is the regular abbreviation utilized for laser. The utilization of lasers in dentistry has been advanced since 1960's by Maiman. Dental lasers offer numerous points of interest like keeping away from needles and fast hand pieces, which makes less horrendous experience and improves social administration of the youngster. In this article we wil show how the lasers are used in pediatric patient.
\end{abstract}

Keywords: Laser, Laser fluroscense, Laser analgesia, Mucocele.

\section{Introduction}

Pediatric dentistry is age characterized claim to fame put together not with respect to a specific ability, yet including all parts of kidsadvancement in wellbeing and sickness. Working with kids is not the same as working with grown-ups, it is fundamental to acquainted with age-proper abilities and working, also, advancement. This century has seen approach of headways even pediatric dentistry likewise affected by all such headways. Such changing patterns help us to raise the models by fusing youngster agreeable methodologies into dental consideration. Laser treatment speaks to a primary wellspring of cure in certain fields in medicine and surgery procedure, though in dentistry it is utilized as adjunctive during hard and delicate tissue treatment. The utilization of lasers in dentistry has been developed since 1960's by Maiman. ${ }^{1}$ Initially lasers like ruby were utilized to carious lacquer and dentine. The utilization of various sorts of new lasers empowers pediatric dental specialist to give negligibly obtrusive dentistry to hard and delicate tissue systems with negligible distress, and no pain during and after treatment. ${ }^{2}$ It limited the utilization of infusions, dispensed with the vibrations, smell of ordinary dentistry and was valued by guardians and youngsters. This makes dental visit safer and introduce positive dental response in a kid.

Hard tissue applications

1. Caries detection by laser fluorescence
2. Prevention of enamel and dental caries

3. Caries removal

4. Cavity preparation

5. Pit and fissure sealants

6. Curing light activated resins

7. Laser pediatric crowns

8. Bleaching of vital and non-vital tooth

9. Laser fusion of vertical root fracture

10. Removal of old restorative materials

11. Laser analgesia

12. Orthodontic tooth movement

13. Dental traumatology.

14. Soft tissue uses

15. Exposure of teeth to aid in tooth eruption

16. Frenectomy

17. Ankyloglossia

18. Aphthous ulcers

19. Herpes labialis lesion

20. Leukoplakia

21. Treatment of mucocele

22. Pediatric endodontics

23. Gingival remodeling and Gingivectomy.

Caries detection by laser fluorescence

Conventional methods of diagnosing dental caries, for example, manual examining and radiographic assessment are often incapable in identifying polish deformities, as they might be as well little or out of reach to the indicative device. ${ }^{3}$ Also, manual examining has the capability of animating caries 
because of the iatrogenic harm brought about by the wayfarer. Radiographs, although viable in uncovering advanced phases of caries, are fruitless in distinguishing early caries, particularly in the fissures. ${ }^{4}$ Prevention of enamel caries

Increased acid resistance ${ }^{5}$ in lased enamel by ultrastructural alterations of enamel, as a result of meltingand resolidifying. Enamel micro hardness seems to be related to enamel mineral content, and plays a role in enamel demineralization, as well as in erosion inhibition.

Organic blocking theory: ${ }^{6}$ Partial denaturation of organic matrix may block the diffusion pathway in enamel, resulting in retardation of enamel demineralization.

Combination of reduced enamel permeability and enamel solubility as suggested by Stern et $\mathrm{al}^{7}$ Diminution in the size of the apatite crystal, due to loss of water and $\mathrm{CO}_{2}$, and that the hydroxyapatite crystal could be made more compact after laser irradiation, thus increasing to enamel resistance.

\section{Caries removal using laser}

Laser treatment has the necessities of insignificant intrusive dentistry. The likelihood to remove little region of tainted layer ensures most extreme preservation of the tooth structure. Utilizing the antibacterial property of the Er: YAG laser, sterilize the influenced layer that holds its remineralizing potential. The absence of smear layer after vaporization with laser guarantees a superior maintenance of the composite pitch to the dentine. Setting up the finish surface with a laser before carving gives a superior minimal seal of the composite restoration. ${ }^{8}$

The biophysics of the hard tissue laser incorporates wavelength, vitality thickness, and heartbeat span of laser radiation and properties of the tissue, for example, ingestion, reflection, transmission and dissipating. All dental hard tissues contain different measure of water. ${ }^{9}$ Water particles in the objective tooth are superheated, detonate and thusly, remove tooth structure and caries. A bactericidal impact, commonplace of lasertissue cooperation happens also. Water interceded dangerous tissue evacuation has been demonstrated to be the most proficient way of evacuating tissue while moving negligible warmth to the remaining tooth.

\section{Laser fusion of vertical root fracture}

Dederich $^{10}$ (1999) utilizing introduction parameters of $15 \mathrm{~W}, 0.2 \mathrm{~s}$ and spot distance across of $1.0 \mathrm{~mm}$, in 15 single exposures with normal of $5 \mathrm{~s}$ slip by time among exposures and radiographic investigation at 1year, watched great bone fill of the deformity and agreeable mending at foreordained presentation parameters.

\section{Laser analgesia}

Pain relieving impact on nerves providing oral cavity is by diminishing terminating recurrence of nociceptors with an edge impact by maximal concealment. Span of pain relieving impact can endure for $15 \mathrm{~min}$ endorsing for use on patients having fear to needles. ${ }^{11}$

\section{Frenectomy}

In infant tight maxillary frenum may meddle with appropriate hooking to breastfeeding. In more seasoned youngsters, high frenal connection may prompt mid-line diastema. Laser settings are Er:YAG $30 \mathrm{~Hz}, 50 \mathrm{~mJ}$ and laser vitality is aimed at the inclusion of frenum and territory between two front teeth. Sutures are notrequired. Post-employable period is uneventful. ${ }^{12}$

\section{Apthous Ulcers}

Are difficult and cause issues during eating and talking. Vitality coordinated into the outside of these sores with lasers in the engaged mode expel uncovered nerve endings. Sores can be rendered inhumane at low wattages inside 4 min with light contact mode. ${ }^{13}$

\section{Treatment of Mucocele}

Laser extraction (Picasso, AMD Laser Technologies, USA; wavelength of $810 \mathrm{~nm}$ ) was utilized under nearby anesthesia (2\% lignocaine with 1:80000 epinephrine), utilizing $300 \mu \mathrm{m}$ distance across tip at $1.3 \mathrm{~W}$. Uneventful recuperating without repeat was accounted for. ${ }^{14}$ 


\section{Lasers in Pediatric Endodontics Determination of dental pulp vitality}

The rule of imperative and non-essential determination of dental pulp by laser Doppler flowmetry depends on the progressions in red platelet transition in the mash tissue. ${ }^{15}$ When ordinary pulp is animated by the beat laser at $2 \mathrm{~W}$ and 20 heartbeats every second a good ways off of roughly $10 \mathrm{~mm}$ from the tooth surface, torment is created inside 20-30 s and vanishes two or three seconds after the laser incitement is halted. In intense pulpitis, torment is incited right away after laser application and proceeds for in excess of $30 \mathrm{~s}$ in the wake of halting the laser incitement. ${ }^{16}$

\section{Direct Pulp capping}

Pulp capping is better with sterilization accomplished up than the profundity of $300 \mu \mathrm{m}$. Nearby absense of pain isn't required with laser because of less warmth age in the mash chamber. ${ }^{17}$

\section{Indirect pulp capping}

Laser tissues have points of interest as for control of drain and sanitization and is in this way advantageous for use in direct mash topping. Er, Cr:YSGG laser at 1 $\mathrm{W}, 20 \mathrm{~Hz}$ with $20 \%$ air and $15 \%$ water is utilized. ${ }^{18}$

\section{Pulpotomy}

Fundamental mash removal by laser treatment was one of the most effective medications in Pedodontics as the removal of the mash tissue at agreeable level is acquired. To accomplish coagulation following removal of coronal mash diminished control setting of $30-40 \mathrm{~mJ}$, with tip of hand piece held 3-4 mm away in defocused mode, without water splash, just $30 \%$ air is utilized. $^{19}$

\section{Access cavity preparation and canal preparation}

New kind of Er, Cr:YSGG lasers has been produced for access cavity preparation and development of root canal orifices. The Nd:YAG laser with $2 \mathrm{~W}$ at 20 pps for $1 \mathrm{~s}$ is prescribed for evacuating pulp caries or microbes. It is powerful instrument for killing microorganisms on account of the laser vitality and wavelength attributes. Contaminated root canals are used for this laser treatment mostly. ${ }^{20}$

\section{Conclusion}

Lasers in pediatric dentistry have benefits just as confinements. Despite the fact that American Academy of Pediatric Dentistry perceives the utilization of lasers as another option strategy for giving soft and hard tissue dental methods for babies, kids, teenagers, and people with extraordinary human services needs, dental professional requires extra preparing to utilize and apply on pediatric dental patients. In the present situation, lasers can be a valuable to pediatric dental practice.

\section{Source of Funding}

None.

\section{Conflict of Interest}

None.

\section{References}

1. Maiman TH. Stimulated optical radiation in ruby. Nature 1960;187:493-4.

2. Arcoria CJ, Lippas MG, Speros P, Wagner MJ. Pulpal effects of argon: Fluoride excimer laser irradiation and acid-etching of rat molar enamel. J Dent 1992;20:100-7.

3. Karlsson L, Tranceus S. Supplementary methods for detection and quantification of dental caries. J Laser Dent 2008;16:6-14.

4. Walsh LJ. The current status of laser applications in dentistry. Aust Dent J 203;48:146-55.

5. Morioka T, Tagomori S, Nara Y. Application of Nd: YAG laser and fluoride in the prevention of dental caries. Lasers Dent 1989;46:53-61.

6. Miseendino LJ, Pick RM. Lasers in Dentistry. Chicago: Quintessence Pub. Co.1995.

7. Stern RH, Vahl J, Sogannes RF. Ultrastructural observations on pulsed carbondioxide laser effects. J Dent Res 1972;51:455-60.

8. Pamela KD, Joel MW, José EP, Furnish G, Silveira A, Frederick MP. The safety and effectiveness of an Er: YAG laser for caries removal and cavity preparation in children. Med Laser Appl 2001;16:215-22.

9. Coluzzi DJ. Atlas of Laser Applications in Dentistry. Illinois: Quintessence Publishing Co. Inc.; 2007.

10. Dederich DN. CO2 laser fusion of a vertical root fracture. $J$ Am Dent Assoc 1999;130:1195-9.

11. Pillai R, Sujathan UN, Jacob AS, Abdulsalim A, Sainudeen S. Hard tissue lasers: An insight. J Interdiscip Dent 2014;14:110-7.

12. Limpanichkul W, Godfrey K, Srisuk N, Rattanayatikul C. Effects of lowlevel laser therapy on the rate of orthodontic tooth movement. Orthod Craniofac Res 2006;9:38-43. 
13. Buchalla W, Attin T. External bleaching therapy with activation by heat, light or laser - A systematic review. Dent Mater 2007;23:586-96.

14. Pandey R, Pathakota KR, Koppolu P, Bolla V. Treatment of mucocele with diode laser. J Dent Lasers 2013;1:43-6.

15. Vlacic J, Meyers IA, Kim J, Walsh LJ. Laser-activated fluoride treatment of enamel against an artificial caries challenge: Comparison of five wavelengths. Aust Dent $J$ 2007;52:101-5.

16. Fox JL, Yu D, Otsuka M, Higuchi WI, Wong J, Powell G et al. Combined effects of laser irradiation and chemical inhibitors on the dissolution of dental enamel. Caries Res 1992;26:333-9.

17. Kotlow L. Diagnosis and treatment of ankyloglossia and tied maxillary fraenum in infants using Er: YAG and 1064 diode lasers. Eur Arch Paediatr Dent 2011;12:106-12.
18. Toomarian L, Fekrazad R, Sharifi D, Baghaei M, Rahimi $\mathrm{H}$, Eslami B. Histopathological evaluation of pulpotomy with Er, Cr: YSGG laser vs formocresol. Lasers Med Sci 2008;23:443-50.

19. Rooney J, Midda M, Leeming J. A laboratory investigation of the bactericidal effect of a NdYAG laser. Br Dent $J$ 1994;176:61-4.

20. Pozza DH, Fregapani PW, Xavier CB, Weber JB, Oliveira MG. CO(2), Er: YAG and Nd: YAG lasers in endodontic surgery. J Appl Oral Sci 2009;17:596-9.

How to cite this article: Hassan SA, Bhateja S. Use of lasers in pediatric dentistry- A review. J PaediatrNurs Sci 2019;2(4):95-8. 